\title{
BMJ Open Can the Easter break induce a long-term break of exercise routines? An analysis of Danish gym data using a regression discontinuity design
}

\author{
Eskild Klausen Fredslund, ${ }^{\oplus 1,2}$ Anja Leppin ${ }^{3}$
}

To cite: Fredslund EK, Leppin A. Can the Easter break induce a long-term break of exercise routines? An analysis of Danish gym data using a regression discontinuity design. BMJ Open 2019:9:e024043. doi:10.1136/ bmjopen-2018-024043

- Prepublication history and additional material for this paper are available online. To view these files, please visit the journal online (http://dx.doi. org/10.1136/bmjopen-2018024043).

Received 9 May 2018

Revised 14 November 2018 Accepted 18 December 2018

Check for updates

(c) Author(s) (or their employer(s)) 2019. Re-use permitted under CC BY-NC. No commercial re-use. See rights and permissions. Published by BMJ.

${ }^{1}$ Department of Public Health, Syddansk Universitet Det Sundhedsvidenskabelige Fakultet, Odense, Denmark ${ }^{2}$ VIVE - The Danish Center for Social Science Research, Aarhus, Denmark

${ }^{3}$ Department of Public Health, University of Southern Denmark Esbjerg, Denmark

Correspondence to

Eskild Klausen Fredslund; esfr@vive.dk

\section{ABSTRACT}

Objectives Many sedentary individuals are aware of the health benefits of regular physical activity and start becoming more physically active. Yet, despite good intentions, many struggle to keep up initial exercise levels and experience a decline in exercise frequency. A possible explanation is that it is hard to establish habits or routines, and that such routines - once established — might be easy to break. In this paper, we analyse whether a break in habitual/routine behaviour -induced by the Easter holidays — results in individuals exercising less after the break.

Methods The study included a sample of 1210 members of a Danish chain of fitness centres who were gym members at least since the preceding New Year's Day. Participants granted access to gym attendance data, which were automatically recorded when entering the gym. We use a regression discontinuity design encompassing a time period of 10 weeks prior to and 10 weeks after Easter.

Results We found a significant and relevant discretionary drop in exercise frequency right after the Easter holidays of 0.24 times per week $(p=0.001$ ) corresponding to a fall of $12.25 \%$ compared with the week prior to the Easter holidays. The effect was especially profound for individuals below retirement age and for individuals who had attended the gym with a higher frequency (twice a week or more) in the 6 weeks prior to the Easter break.

Discussion This information is potentially relevant for helping individuals maintain an exercise habit. Motivational support should focus on the time period after normative breaks, such as Easter or other holidays.

\section{INTRODUCTION}

The evidence for beneficial effects of regular physical activity on different aspects of health is substantial. ${ }^{1-5}$ Yet, in many countries, sizeable proportions of the population remain sedentary or stay below the level of physical activity considered necessary for achieving those health gains. ${ }^{67}$ The problem seems less that people are not aware of the benefits but good intentions are not kept up for a long term or even medium term. January, in particular, seems to feature full gyms, but regular attendance rates tend to dwindle as
Strengths and limitations of this study

We have a comparably large sample of members of a chain of fitness centre in Denmark.

We use registered gym attendance at the gym which is an objective measure.

- We have no direct measure of habit strength.

- The regression method is possibly sensitive to discrete changes in weather or other outside factors.

time passes, and over the course of the year many of those, who started out believing they really wanted to make a change, feel unable to stay the course. ${ }^{8}$

Research on motivational processes involved in physical activity has long been dominated by cognitive-intentional models of health behaviour, such as theory of planned behaviour or protection motivation theory, ${ }^{9}{ }^{10}$ which focus on consciously regulated and controlled cognitive processes. ${ }^{11}$ More recently, however, dual process models have met with increasing attention. While these approaches have been using different labels for the processes involved, such as 'reflective-impulsive', 'heuristic-systematic' or 'system 1' versus 'system 2', ${ }^{12-14}$ they all posit that behaviours result from two distinct parallel mechanisms. While one of these processes is conscious-rational, intentional-goal-directed and therefore often rather slow, the other is non-conscious, automatic-reflexive, effortless and rapid.

An important mechanism within the automatic-reflexive system is the formation of habits. These are behavioural patterns acquired by associative learning processes where certain consistently occurring contextual stimuli come to be cognitively associated with specific behavioural responses. ${ }^{15}$ Over time, people develop 'response dispositions' towards reacting in the same way when they find themselves in the same contextual 
conditions. ${ }^{16-18}$ Thus, an automatism is developed where encountering a certain context alone is sufficient to cue the response, independent of any explicit incentive structure, which might initially have motivated and triggered the behaviour. ${ }^{15} 18$ Empirical support for this notion comes from a meta-analysis of 22 studies conducted by Gardner et al who found a significant association of habit strength with physical activity $(\mathrm{r}=0.43) .{ }^{15}$

Behavioural cues may evolve from many different sources, among them not only the physical environment but also certain time points, such as specific days, or particular persons associated with the behaviour. Cues that can induce physical activity could, for instance, be familiar exercise equipment or people one is used to exercise with and also regularly recurring time points, which may generate 'temporal practice structures' ${ }^{19} 20$ Thus, individuals may build physical activity into their daily routines by exercising when going to or from work, before breakfast on Saturday or Sunday mornings or at any other point in time which returns at regular intervals. ${ }^{21}$ In a study of regular exercisers, nearly $90 \%$ reported having a particular location or a specific time, which cued or prompted them into exercise. ${ }^{22}$

Habit formation has also gained attention in the field of behavioural economics. Becker and Murphy, ${ }^{23}$ for instance, introduced a 'theory of rational addiction' which does not focus on underlying mechanism of habit acquisition. According to Becker and Murphy, past consumption of certain goods or performance of certain activities simply increases future utility of these goods or activities ('adjacent complementarity') whereby a habit is created.

Charness and Gneezy conducted a randomised controlled trial (RCT) with students who all had received a gym membership as part of their enrolment fees. ${ }^{24}$ Those who were additionally monetarily incentivised for attending the gym at least two times a week over a 4-week period not only attended more frequently than non-incentivised students during the intervention period but also for a 7-week period after removal of the incentives. This is consistent with the assumption that conscious, goal-oriented behaviour may become routinised and habitual over time.

However, questions remain. Once established, how easily can habits or behavioural routines be broken when environmental, time-related or social cues either fail to appear or cannot be acted on because a person's physical or social context changes? Such changes are common in most people's lives, and one of the most frequent and normative interruptions of daily routines is public or private holidays. While welcome to most people, could a downside be that such holidays disrupt people's cues for exercise? In a replication of the study by Charness and Gneezy, Acland and Levy likewise found higher gym attendance rates for incentivised students, ${ }^{25}$ and these rates were upheld over a period of time after incentives had been removed indicating that habits may have formed. However, over a longer time period, which included the winter term break, the initial treatment effect disappeared. This suggests that habits or routines established over a shorter term may be broken by external interruptions, such as holiday breaks. To our knowledge, however, no studies have yet investigated whether such behavioural effects by 'external disruptors' would also occur for larger-scale population-based samples who have not been specifically incentivised for physical activity by monetary rewards but are following their natural motivational trajectories.

This is why we used the present study to investigate whether a short, temporary disruptor imposed by the Easter holidays can lead to a substantial drop in gym attendance in a population of citizens of Denmark who had been gym members for at least 3 months. Since neither being a continuous gym member nor even regular gym attendance can guarantee the existence of a habit, the focus of the present study was on behavioural routines rather than on habits in the narrower sense of the term. However, we aimed at getting deeper insight by further comparing potential effects of the break between members with higher as compared with lower regular gym attendance rates in the weeks prior to Easter, that is people with potentially stronger as compared with weaker behavioural routines. Furthermore, we compared effects for gym members above and below average retirement age, as these two groups can be expected to be differently affected in their daily routines by a public holiday.

Research questions were as follows:

- Is there a discontinuous drop in gym attendance after the Easter break compared with a 10 -week period before the break?

- Is a discontinuous drop more prevalent or more pronounced in gym members with higher as compared with lower levels of prior gym attendance and in people below and above retirement age?

\section{METHODS}

\section{Data collection}

Data were collected in collaboration with Fitness. $d k$, which has about 125000 members in 47 centres across Denmark.

\begin{tabular}{ll}
\hline Table 1 Sample characteristics & \\
\hline Variable & \\
\hline Women & $62.9 \%$ \\
\hline Men & $37.1 \%$ \\
\hline Age (M/SD) & $42.4(13.9)$ \\
\hline Above retirement age ( $\geq 65$ years) & $6.9 \%$ \\
\hline Below retirement age (<65years) & $93.1 \%$ \\
\hline $\begin{array}{l}\text { Weekly attendance two times or more prior to } \\
\text { Easter break }\end{array}$ & $19.6 \%$ \\
\hline $\begin{array}{l}\text { Weekly attendance below two times prior to } \\
\text { Easter break }\end{array}$ & $80.4 \%$ \\
$\mathrm{~N}$ & 1210 \\
\hline
\end{tabular}

Estimating the effect of an interruption. 


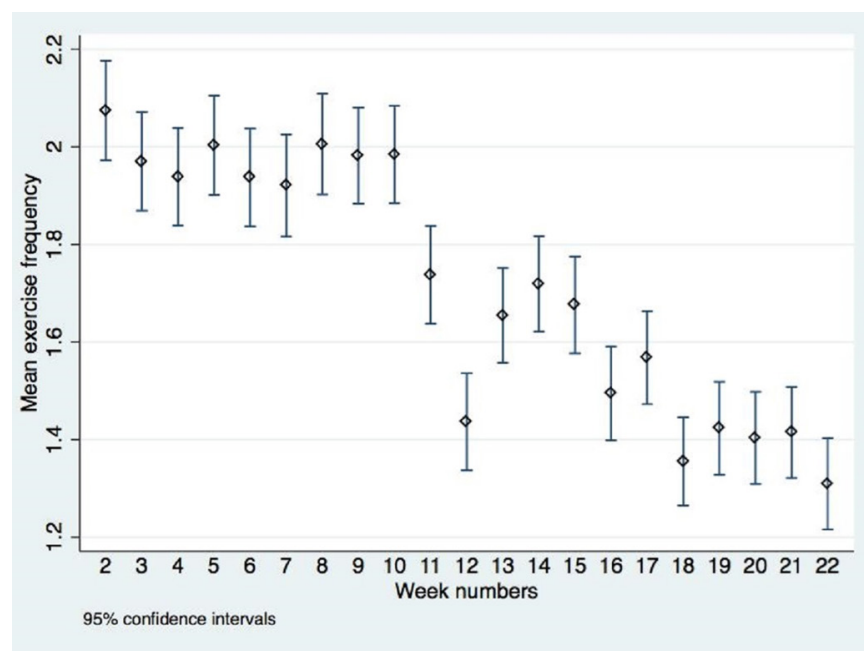

Figure 1 Average gym attendance in weeks 2-22 in 2016.

Data collection took place in two steps-through an online survey to fitness. $d k$ members, and by subsequent observational data about gym attendance from the centres. Before they filled out the questionnaire, potential participants received information about the study and were informed that by filling out and submitting the questionnaire they gave permission to the use of their self-report and their gym attendance data for the purposes of the study. The questionnaire was distributed to members of fitness. $d k$ who had signed up to the weekly electronic newsletter (approximately 80000 members received the newsletter), which 7 February 2016 and the 6 March 2016, contained an electronic link to the questionnaire.

A total of 4987 members activated the questionnaire, 1687 (34 \%) of who answered all questions, 2132 (43\%) did not answer any questions and 1168 (23\%) answered some questions. The study sample included only those 1687 who provided fully completed questionnaires. Analysis was restricted to members who had signed up before
Table 2 Regression discontinuity estimates of the local average treatment effect on average gym attendance without week 12 and without weeks 11 and 12

\begin{tabular}{lll}
\hline & $\begin{array}{l}\text { Without } \\
\text { week 12 }\end{array}$ & $\begin{array}{l}\text { Without weeks } \\
\mathbf{1 1} \text { and 12 }\end{array}$ \\
\hline RD estimate & -0.0913 & -0.243 \\
$\mathrm{P}$ value & $(0.188)$ & $(0.001)$ \\
Drop in \% relative to week 10 & $4.60 \%$ & $12.25 \%$ \\
$\mathrm{~N}$ & 24200 & 22990 \\
\hline
\end{tabular}

The $\mathrm{N}$ reported is the number of members times the number of weeks included in the analysis. $\mathrm{RD}$, Regression discontinouity.

New Year's Day 2016 and stayed members during the entire period of analysis from 1 January to 15 September 2016. This yielded a sample of 1210 respondents. For the present article, only behavioural data regarding frequency of gym attendance provided by fitness.dk were used. Members check in via a key card each time they work out, which means that daily data on an individual level were available. This was supplemented by demographic data and also delivered by fitness. $d k$.

To account for other possible changes around the Easter break, which could explain a drop in gym attendance frequency during the critical time span, we accessed historical weather data from The Danish Meteorological Institute and data on the development of the influenza season from Denmark's Statens Serum Institut.

\section{Estimating the effect of an interruption}

We used a regression discontinuity design in analysing a potential drop in exercise frequency after the Easter holidays with time as the forcing variable. As members were observed each week, standard errors were clustered. Bin size was chosen to be 1 week as respondents in the

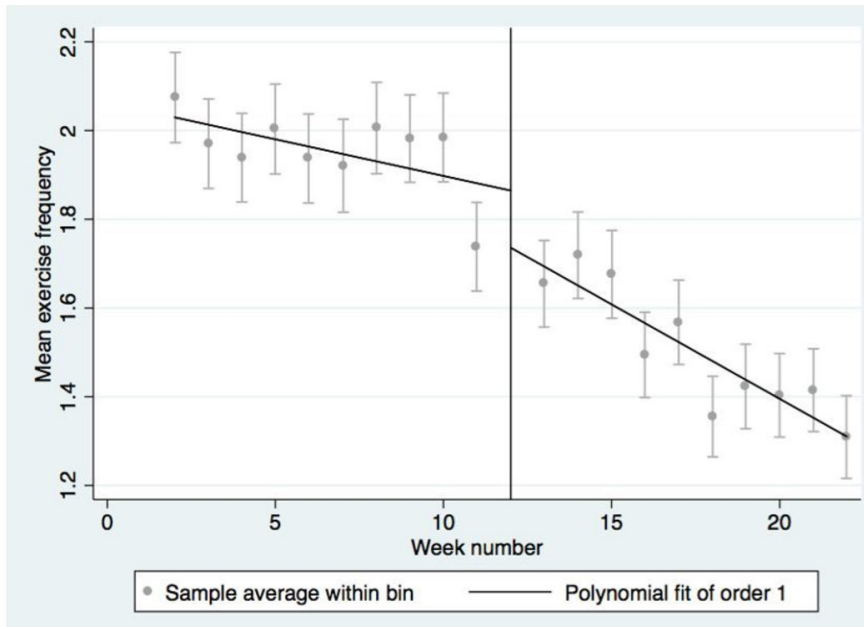

without week 12

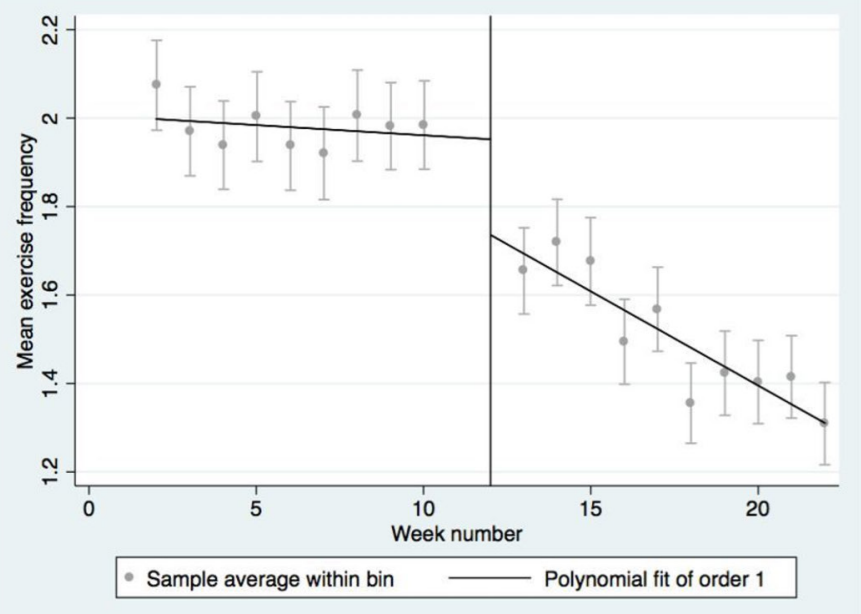

without weeks 11 and 12

Figure 2 Average gym attendance in weeks 2-22 in 2016 for the entire sample without week 11 and without weeks 11 and 12. Regression lines were produced using regression discontinuity analysis. 
Table 3 Regression kink estimates of the change in exercise frequency decline before and after the Easter break

\begin{tabular}{ll}
\hline & Change in slope \\
\hline RD kink estimate & -0.061 \\
P-value & $(0.113)$ \\
$\mathrm{N}$ & 22969 \\
\hline
\end{tabular}

The $\mathrm{N}$ reported is the number of members times the number of weeks included in the analysis.

pilot study had indicated that they planned their exercise level on a weekly basis.

In the analysis, we focused on a break in habits with the Easter holidays as the external event. The Easter holidays in 2016 were in week 12, from the 21 to 28 March. A regression discontinuity design was used to analyse whether there was a significant drop in exercise the week after the Easter holidays. ${ }^{26}{ }^{27}$ We made no assumptions about whether individuals exercised more or less during the holiday but focused on a possible effect in the following weeks. As we suspected an anticipation effect in the week prior to the Easter break due to members extending the Easter break by a longer holiday, we excluded week 11 in some of the analysis.

With the help of a regression kink design, we further analysed whether the Easter break leads to a change in the rate at which exercise frequency declines.

In further subanalyses, gym members were divided into those above and those below the common retirement age in Denmark (age 65 years) and additionally into individuals who had attended the gym twice a week or more in the 6 weeks prior to the Easter break and those with lower attendance levels. The 6 -week period was chosen based on a common behavior-based definition of time periods during which habits are likely to be established. ${ }^{19}$

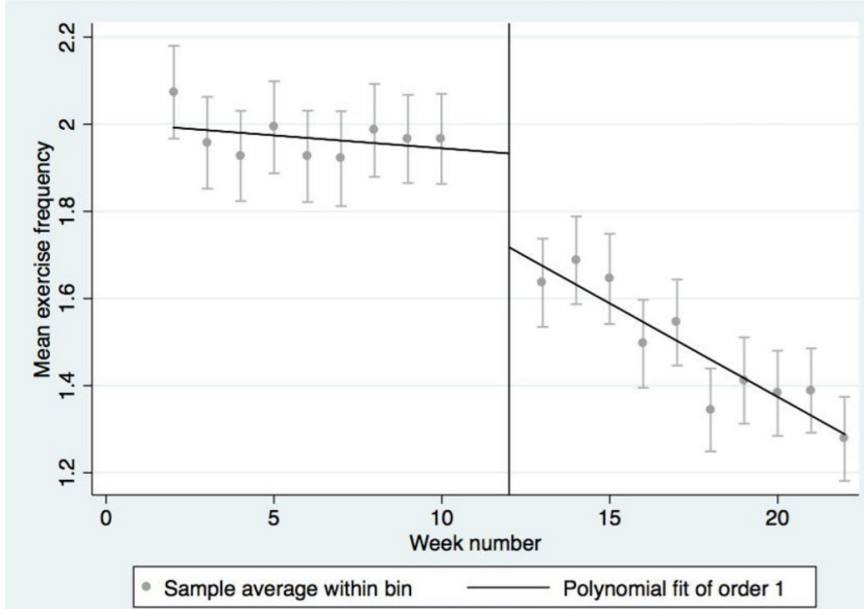

Gym members below retirement age
Data analysis was conducted using Stata 13 and the extension rdrobust. ${ }^{28}$

Prior to initiating the data collection, we were granted approval from the Danish Data Protection Agency (Journal nr. 2014-54-0783) to collect and store the data. Before answering the questionnaire, potential respondents were informed that by answering and submitting the questionnaire, they gave consent for fitness. $d k$ to provide the project with access to their attendance data as well as with demographic information (gender and age). The respondents were also informed that the data would be used for research purposes.

\section{Patient and public involvement}

Members of fitness. $d k$ were not directly included in planning the research process, setting the research question and deciding about the research design. We introduced and described the purpose of the research project to the respondents of the questionnaire. All participants completed this survey on a voluntary basis. The results of the research will be disseminated to fitness. $d k$ but not to the individual members.

\section{RESULTS \\ Sample}

The sample consisted of 1210 gym members, $63 \%$ of whom were women and $7 \%$ older than 65 years, that is above average retirement age in that age cohort (table 1 ). Almost 20\% had attended the gym twice or more in the 6 weeks prior to the Easter break.

\section{Estimating the effect of an interruption}

Figure 1 shows the development of gym attendance frequency 10 weeks before and after the Easter holidays. For the Easter week itself, it was shown that $46 \%$ exercised less compared with week 10 while $20 \%$ exercised more. As we were not interested in measuring the effect

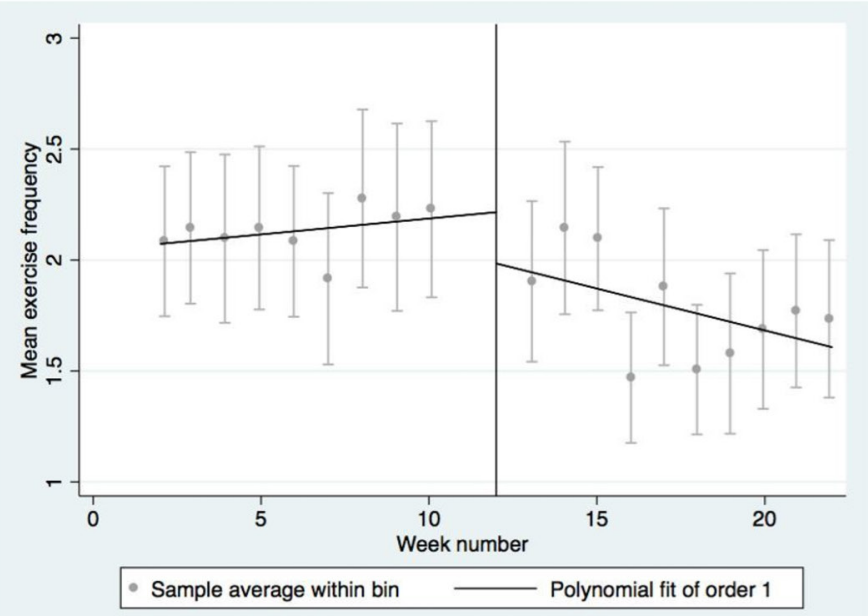

Gym members above retirement age

Figure 3 Average gym attendance in weeks 2-22 in 2016 for gym members below and above retirement age. Regression lines produced using regression discontinuity analysis. 


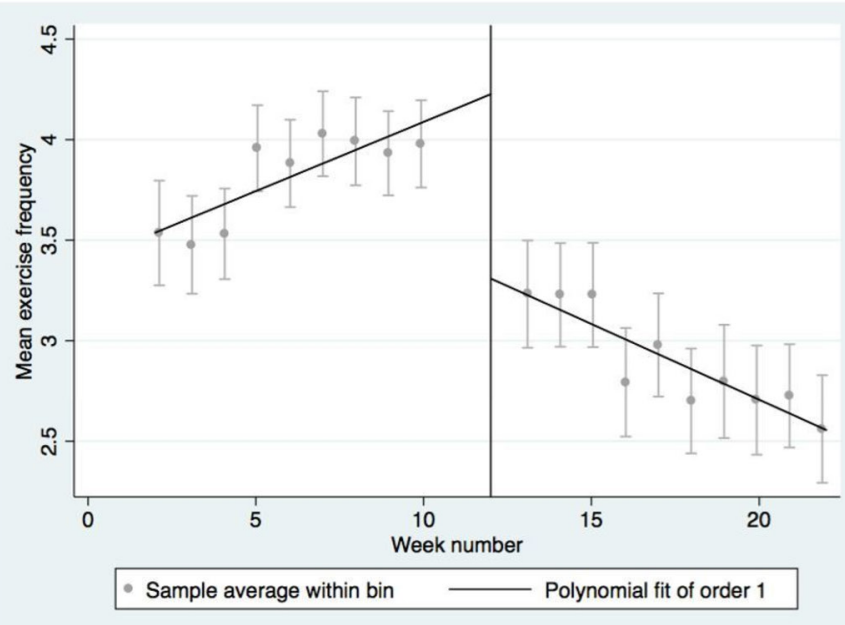

Workout twice a week or more

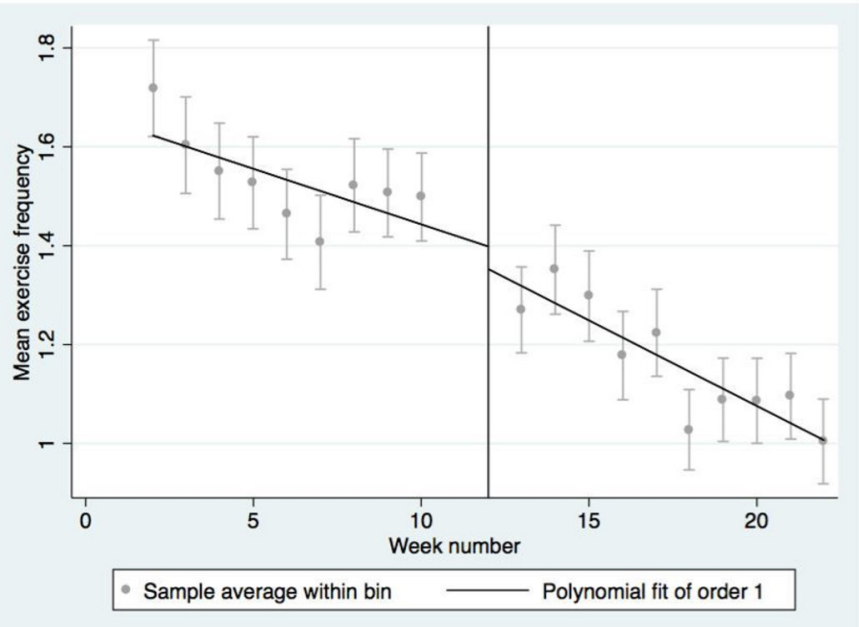

Workout less than twice a week

Figure 4 Average gym attendance in weeks 2-22 in 2016 for gym members attending the gym twice a week or more 6 weeks prior to the Easter break and members attending less frequently. Regression lines produced using regression discontinuity analysis.

of the Easter holidays in week 12, we excluded week 12 in the following analysis. As can be seen in figure 2, it seems that there was in fact a discontinuous shift after the Easter holidays. Additionally, it can be seen that when compared with weeks 8,9 and 10 a substantial drop in gym attendance already occurred in week 11, prior to the Easter holidays.

There was a statistically significant effect of the Easter holidays on exercise activity in the gym after the holiday had ended. This effect, however, was only significant when week 11, that is the week prior to Easter, was excluded (see table 2).

Since Monday in week 13 also was a public holiday, it was checked in a further analysis whether excluding all Mondays affected the results. Findings resembled the results shown in table 2.

We tested whether the slope was steeper after the Easter break than before in a regression kink design present in table 3. Table 3 shows that there was no steeper decline in the frequency of gym attendance after the Easter break compared with before.

\section{Subgroup analyses}

The results of the subgroup analyses are shown in figures 3 and 4 and summarised in table 4 . First, retired gym members did not exhibit a significant decline in attendance, whereas this was the case for the non-retired.

Second, it was only those who had attended the gym on a regular basis, that is, at a minimum of two times a week in the 6 weeks prior to Easter, who were significantly affected by the Easter break, whereas those who had been less regular attenders in the weeks before Easter did not significantly drop in their attendance (see figure 4). We observed a discontinuous drop for regular gym goers but a gradual decline for the ones attending the gym less than twice a week.

As a robustness check for our subgroup analysis, we furthermore performed an analysis on subgroups of individuals who had attended the gym twice a week in 9 weeks prior to Easter or three times a week in 6 weeks prior to Easter. These analyses showed a significant drop in attendance frequency for both these groups (for a presentation of results, see online supplementary appendix A).

As a further robustness check, we analysed whether there were discontinuous changes in weather or the influenza season that could explain a change in behaviour. This was not the case (for a presentation of results, see online supplementary appendix B).

Table 4 Subgroup analysis based on retirement age and regularity of attendance before Easter

Attendance twice a Attendance less than Above retirement age Below retirement age week or more twice a week

\begin{tabular}{lllll}
\hline $\mathrm{RD}$ - estimate & -0.180 & -0.248 & -0.758 & -0.118 \\
$\mathrm{P}$ value & $(0.542)$ & $(0.001)$ & $(0.000)$ & $(0.072)$ \\
Drop in \% relative to week 10 & $8.07 \%$ & $12.6 \%$ & $19.1 \%$ & $7.88 \%$ \\
$\mathrm{~N}$ & 1577 & 21413 & 4503 & 18487
\end{tabular}

The $\mathrm{N}$ reported is the number of members times the number of weeks included in the analysis. 


\section{DISCUSSION}

In this paper, we have shown that a relatively short temporary break can affect behaviour in a population of Danish gym members in a statistically significant and relevant way. We estimated that gym attendance after the Easter holidays dropped by more than 0.2 times per week corresponding to a $12 \%$ drop in activity after the break, and there was no reversal in this downward development in the subsequent weeks but a steady further decline. Thus, the break in gym attendance caused by the Easter holidays disruption does not seem to be compensated for afterwards but seems to function as a starting point for further decline.

When analysing the slope of the decline in exercise frequency before and after the Easter break, we found no significant change due to the Easter break. This, in combination with the analysis of the discontinuous drop in exercise frequency, indicates that the Easter break affected the level of exercise frequency but not the rate at which the frequency dropped.

The present findings are relevant since they contribute to pinpointing specific stumbling blocks people may face in establishing healthy physical activity routines. 'Afterbreak-periods' could accordingly be used as starting points for future interventions trying to help people get back on track. Prior studies have shown that holiday seasons, such as Christmas or Thanksgiving, are associated with weight gain due to increased food intake, ${ }^{29-31}$ and a few studies have also shown a negative effect of these seasons on physical activity in special groups such as the overweight or children. ${ }^{32} 33$ Also, it has been demonstrated by an experimental study with students how physical activity habits can be compromised by a break period, ${ }^{25}$ but no larger-scale study with a less selected population has as yet investigated such effects for exercise activity.

In Denmark, the Easter break involves a 5-day work-free period for most, and quite many take additional holidays to go on a longer vacation. For those who stay home, Easter commonly involves commitments such as family visits and day-trips/activities with kids who are on vacation from school, which may prevent parents going to the gym. Thus, there may be barriers, which lead to a deliberate, temporal change in exercise intentions. Beyond such conscious influences, however, the change in daily routines may affect prior automatisms which before had cued people towards going to the gym. ${ }^{14}$ Thus, changes in the physical or social environment may have implied an absence of time cues such as going to the gym before/ after work, spatial cues such as passing the gym on the way to work, meeting colleagues to work out with, etc. In relation to the habit definition by Becker and Murphy, ${ }^{23}$ the drop in exercise frequency during the holiday would negatively affect the utility of exercise after the Easter break, leading the members to exercise less in the future.

In any case, our data suggest that such a temporary interruption actually may have longer-term consequences for some. It seems that the break was able to weaken a response tendency to go to the gym to a degree where a previous automatic association was broken and a switch back to the prior context after the end of the break period did not restore prior activity patterns.

Interestingly, subanalyses revealed that this disruption effect was primarily due to study participants who had been attending the gym on a more regular basis for the preceding 6 weeks, that is those who were most likely to actually have established a habit or at least a behavioural routine. It seems therefore that such routines may be quite fragile and can be disrupted comparatively easily. This is in line with the findings reported by Acland and Levy where an apparent formation of gym attendance habits by students was cancelled out by a winter term break. $^{25}$

It is important to note that the attendance drop in those with established routines or habits does not imply that those without such habits in the weeks prior to Easter were 'better off' in terms of gym-based exercise frequency. Instead, this group, which per definition started out from a lower level, seems to have been sliding along a steady downward slope over time. The Easter break, on the other hand, affected precisely the group with the best prognosis in terms of long-term maintenance of exercise activity: those who actually had been able to establish a routine or habit. ${ }^{151718}$

In further subanalyses, we observed that different from persons below 65 years and therefore highly likely to be in the work force, those 65 years and above, who in that age cohort in Denmark mostly are retired, did not significantly decrease their gym attendance after the Easter break. This is consistent with the assumption that a change of situational context may play a role for a break in habits/routines. Since retired persons are unrestricted by working hours, they are less likely to experience differences in their daily routines due to a general holiday period. Also, pensioners tend to avoid school holidays for going on vacation themselves, so a complete change of scene is less likely to have occurred in this group as compared with those still in the work force and with children bound by school holidays. Consequently, the retired may have had an easier time in carrying over their gym attendance routines to the time period after Easter.

When evaluating the findings, it needs to be noted that the criterion used in the present study for distinguishing those with a routine or habit from those without may be debated. Kaushal and Rhodes actually suggested a minimum criterion of four exercise bouts per week over a 6 -week period. ${ }^{19}$ Since only comparatively few persons among our sample matched this criterion, which probably is also due to the fact that we did not assess all exercise behaviour but just exercise in the gym, we lowered the limit to two attendances per week over a 6 -week period. Furthermore, it has been argued that habits should not be assessed based on behavioural frequency alone but as presence of a non-conscious, automatic regulatory process. $^{15203435}$

As a robustness check, we ran the analysis with two further and more strict definitions of a routine-analysing 
members who exercised twice a week in 9 weeks and three times a week in 6 weeks. These groups showed similar results as our primary subgroup who exercised twice a week in 6 weeks. However, it can still not be excluded that the 'drop effect' may have been smaller if we had included a more direct measure of habit strength, and we can therefore only draw conclusion about a break of routines rather than habits.

Strongly engrained habits, on the other hand, might have withstood the disruption by the holiday break, be it due to firmer associational ties between environmental cues and behaviour and/or due to rewarding and reinforcing physiological (eg, dopamine-system-mediated) reaction patterns that are built over time and missed when absent. ${ }^{36}$ Furthermore, it has been suggested that habitual behaviour may be related to the formation of self-schema. Schemata are cognitive structures in terms of generalised and stable reflections about the self which relate to aspects considered important to the self-concept. ${ }^{37}{ }^{38}$ Kendzierski and Whitaker, in a study on dieting behaviour in female students, actually found that while both schematic and aschematic students lapsed from their dieting during semester breaks, it was the schematics who were later able to revert to their prior dieting behaviour, whereas the aschematic students did not. ${ }^{39}$ Related to the present findings, it is thus possible that the 'drop effect' is mainly due to those without firmly established behavioural patterns and/or establish self-schemata for physical activity. This is an avenue worthwhile investigating by further studies.

\section{Study strengths and limitations}

A major strength of the present study is the large sample size and that it encompasses a wider age range than many other studies, which have often focused on students. Furthermore, the study included people with different routine frequency levels of gym attendance activity.

A strength regarding measurement is that due to the use of an 'objective' measure of gym attendance, there was no bias due to self-report/social-desirability as well as no selective loss to follow-up.

As for data collection, a limitation of the study is that a self-selection effect is likely to have affected the initial sample, as it probably was mainly the higher educated and possibly also those with a higher motivation for exercise who agreed to participate in the study by filling out the questionnaire. We thus cannot claim to have a representative sample of gym members or the population in general.

A regression discontinuity design was used to analyse whether the Easter break induces a break in habits of members of a fitness centre. While this is a recommended design for evaluating 'real-life' processes, which cannot be investigated with the help of an RCT, competing extraneous influences on exercise frequency cannot be excluded. That is, the regression discontinuity design is only identified if no confounders change discontinuously around the Easter break, such as, for instance, a shift in weather (spring and warmer temperatures) or influenza activity. Using weather and influenza data, we have shown, however, that there was no discontinuity in these two factors during the respective time span, which suggests that they were not the driving force behind the observed changes. We cannot exclude, however, that there were other unobserved factors, which could have influenced gym attendance. The main concern in this context is that independent of the weather members could have started exercising outside the gym and thus compensated for any drop in gym attendance. In particular, this could have been the case for those who left their homes for a vacation. If these people kept on engaging in the 'new' behaviours, after the break, there might not have been a decrease in exercise frequency but just a shift in type of exercise. However, such an effect is likely to have affected all investigated subgroups in a similar way. Also, since gyms require a considerable financial contribution and most people prefer to get some 'return on investment' instead of making a similar effort 'for free' as well as due to the fact that gyms offer different kinds of exercise than can be performed outside, it is unlikely that the drop in frequency could be fully explained by such a shift.

\section{CONCLUSION}

In our analysis, we have shown that there is a significant and relevant drop in gym attendance following an external interruption induced by the Easter break. Subanalyses indicated that this effect was mainly due to groups with more consistently high attendance in the weeks prior to Easter and in those more likely to experience a context change, that is, those below 65 years as compared with those above retirement age, which is consistent with the assumption that the break actually more permanently disrupted established exercise routines for some.

This information is relevant for both health educators and fitness centres concerned with helping individuals maintain a steady exercise habit. Potential efforts should be focused specifically at the time periods after normative breaks, such as Easter, Christmas or other faith-based holidays but possibly also periods like common summer vacations. If there is no automatism in resuming routines or habits, people may need specific additional motivational input, for instance, in terms of small reminders or incentives, to start attending the gym again and thus building up their habits once more.

Contributors EKF contributed to the study concept, data collection, data analysis and interpretation and drafting of the manuscript. AL contributed to the study concept, interpretation and drafting of the manuscript.

Funding The work was supported by University of Southern Denmark and The Health Foundation (application 17-B-0066).

Competing interests None declared.

Patient consent for publication Not required.

Ethics approval No ethical approval was needed following the Guidelines from The National Committee on Health Research Ethics on research solely based on questionnaire and register data (The Committee Law § 14). 
Provenance and peer review Not commissioned; externally peer reviewed.

Data sharing statement Data used to this project are not available to any second party due to the agreement with the research subjects.

Open access This is an open access article distributed in accordance with the Creative Commons Attribution Non Commercial (CC BY-NC 4.0) license, which permits others to distribute, remix, adapt, build upon this work non-commercially, and license their derivative works on different terms, provided the original work is properly cited, appropriate credit is given, any changes made indicated, and the use is non-commercial. See: http://creativecommons.org/licenses/by-nc/4.0/.

\section{REFERENCES}

1. Biddle SJ, Asare M. Physical activity and mental health in children and adolescents: a review of reviews. Br J Sports Med 2011;45:886-95.

2. Biswas A, Oh PI, Faulkner GE, et al. Sedentary time and its association with risk for disease incidence, mortality, and hospitalization in adults: a systematic review and meta-analysis. Ann Intern Med 2015;162:123-32.

3. Bize R, Johnson JA, Plotnikoff RC. Physical activity level and healthrelated quality of life in the general adult population: a systematic review. Prev Med 2007;45:401-15.

4. Hardefeldt PJ, Penninkilampi R, Edirimanne S, et al. Physical activity and weight loss reduce the risk of breast cancer: a meta-analysis of 139 prospective and retrospective studies. Clin Breast Cancer 2018;18:e601-12.

5. Lobelo F, Rohm Young D, Sallis R, et al. Routine assessment and promotion of physical activity in healthcare settings: a scientific statement from the American Heart Association. Circulation 2018;137:495-522.

6. Special Eurobarometer 412. Sport and physical activity. Brussels: European Commission, Directorate General for Education and Culture, 2014.

7. Hallal PC, Andersen LB, Bull FC, et al. Global physical activity levels: surveillance progress, pitfalls, and prospects. The Lancet 2012;380:247-57.

8. FIA. Winning the retention battle. London: Fitness Industry Association, 2001.

9. Ajzen I. The theory of planned behavior. Organ Behav Hum Decis Process 1991;50:179-211.

10. Rogers RW. A protection motivation theory of fear appeals and attitude change1. J Psychol 1975;91:93-114.

11. Rhodes RE, Yao CA. Models accounting for intention-behavior discordance in the physical activity domain: a user's guide, content overview, and review of current evidence. Int J Behav Nutr Phys Act 2015;12:9.

12. Strack F, Deutsch R. Reflective and impulsive determinants of social behavior. Pers Soc Psychol Rev 2004;8:220-47.

13. Chaiken S, Trope Y. Dual-process theories in social psychology. New York, NY: Guilford Press, 1999.

14. Stanovich KE, West RF. Individual differences in reasoning: implications for the rationality debate? Behav Brain Sci 2000;23:645-65.

15. Gardner B, de Bruijn GJ, Lally P. A systematic review and metaanalysis of applications of the Self-Report Habit Index to nutrition and physical activity behaviours. Ann Behav Med 2011;42:174-87.
16. Lally P, Wardle J, Gardner B. Experiences of habit formation: a qualitative study. Psychol Health Med 2011;16:484-9.

17. Wood W, Neal DT. A new look at habits and the habit-goal interface. Psychol Rev 2007;114:843-63.

18. Wood W, Rünger D. Psychology of habit. Annu Rev Psychol 2016;67:289-314.

19. Kaushal N, Rhodes RE. Exercise habit formation in new gym members: a longitudinal study. J Behav Med 2015;38:652-63.

20. Pimm R, Vandelanotte $C$, Rhodes RE, et al. Cue consistency associated with physical activity automaticity and behavior. Behav Med 2016;42:248-53.

21. Lally P, Gardner B. Promoting habit formation. Health Psychol Rev 2013;7(sup1):S137-58.

22. Tappe K, Tarves E, Oltarzewski J, et al. Habit formation among regular exercisers at fitness centers: an exploratory study. J Phys Act Health 2013;10:607-13.

23. Becker GS, Murphy KM. A theory of rational addiction. J Polit Econ 1988;96:675-700.

24. Charness G, Gneezy U. Incentives to exercise. Econometrica 2009;77:909-31.

25. Acland D, Levy MR. Naiveté, projection bias, and habit formation in gym attendance. Manage Sci 2015;61:146-60.

26. Angrist JD, Pischke J-S. Mostly harmless econometrics: an empiricist's companion. Princeton university press: Princeton, NJ, 2008.

27. Hausman C, Rapson DS. Regression discontinuity in time: considerations for empirical applications. Annu Rev Resour Economics 2018;10:533-52.

28. Calonico S, Cattaneo MD, Titiunik R. Robust data-driven inference in the regression-discontinuity design. Stata $J$ 2014;14:909-46.

29. Díaz-Zavala RG, Castro-Cantú MF, Valencia ME, et al. Effect of the holiday season on weight gain: a narrative review. J Obes 2017;2017:1-13.

30. Helander EE, Wansink B, Chieh A. Weight gain over the holidays in three countries. N Engl J Med 2016;375:1200-2.

31. Reid R, Hackett AF. Changes in nutritional status in adults over Christmas 1998. Journal of Human Nutrition and Dietetics 1999;12:513-6.

32. Ma Y, Olendzki BC, Li W, et al. Seasonal variation in food intake, physical activity, and body weight in a predominantly overweight population. Eur J Clin Nutr 2006;60:519-28.

33. Rich C, Griffiths LJ, Dezateux C. Seasonal variation in accelerometerdetermined sedentary behaviour and physical activity in children: a review. Int J Behav Nutr Phys Act 2012;9:49.

34. Gardner B. A review and analysis of the use of 'habit' in understanding, predicting and influencing health-related behaviour. Health Psychol Rev 2015;9:277-95.

35. Verplanken B, Orbell S. Reflections on past behavior: a self-report index of habit strength1. J Appl Soc Psychol 2003;33:1313-30

36. Flack KD, Johnson L, Roemmich JN. Aerobic and resistance exercise reinforcement and discomfort tolerance predict meeting activity guidelines. Physiol Behav 2017;170:32-6.

37. Markus H. Self-schemata and processing information about the self. J Pers Soc Psychol 1977;35:63-78.

38. Kendzierski D. Self-schemata and exercise. Basic Appl Soc Psych 1988;9:45-59.

39. Kendzierski D, Whitaker DJ. The role of self-schema in linking intentions with behavior. Personality and Social Psychology Bulletin 1997;23:139-47. 